\title{
Teori Gestalt (Meningkatkan Pembelajaran Melalui Proses Pemahaman)
}

\section{Gestalt Theory (Improve Learning Outcomes Through The Understanding Process)}

\author{
Sabilla Irwina Safitri ${ }^{1}$, Dwi Saraswati ${ }^{2}$, Esa Nur Wahyuni ${ }^{3}$ \\ 1,2,3 Magister Pendidikan Guru Madrasah Ibtidaiyah, Universitas Islam Negeri Maulana \\ Malik Ibrahim Malang \\ e-mail: ${ }^{1}$ sabillairwinasafitri123@gmail.com, ${ }^{2}$ dwisaraswati71216@gmail.com, \\ 3esanw@uin-malang.ac.id
}

\begin{abstract}
Abstrak: Teori Gestalt memandang bahwa pembelajaran tidak hanya tentang rangsangan dan respon tetapi lebih pada pemahaman tentang suatu masalah yang mampu menarik kesimpulan baru yang berwawasan. Pencetus teori Gestalt termasuk Max Wetheimer, Wolfgang Kohler dan Kurt Kofka. Dalam teori Gestalt terdapat beberapa hukum yaitu hukum kedekatan, hukum ketertutupan dan hukum kesamaan. Diantara prinsip pembelajaran Gestalt adalah pembelajaran melalui wawasan (pemahaman), pembelajaran merupakan reorganisasi dari pengalaman, pembelajaran akan lebih berhasil bila sesuai dengan minat siswa. Sedangkan prinsip persepsi Gestalt termasuk prinsip kontinuitas dan hubungan figur-ground. Kekuatan teori Gestalt adalah anak mampu membangun suatu masalah menjadi pengetahuan atau pemahaman baru, namun teori Gestalt ini juga memiliki kelemahan, yakni teori Gestalt tidak bisa diterapkan pada maeri-materi tertentu.
\end{abstract}

Kata Kunci: Teori Pembelajaran, Gestalt, Pemahaman.

Abstract: Gestalt theory views that learning is not only about stimuli and responses but rather about understanding a problem faced which is able to draw new insightful conclusions. Gestalt characters include Max Wetheimer, Wolfgang Kohler and Kurt Kofka. In Gestalt theory, there are several laws, namely the law of closeness, the law of closure and the law of equality. Among the principles of Gestalt learning is that learning through insight (understanding), learning is a reorganization of experiences, learning will be more successful when it comes to interests. Meanwhile, the principles of Gestalt perception include the principle of continuity and Figure-ground relationship. The strength of Gestalt theory is that children are able to reconstruct a problem into new knowledge or understanding, however in the Gestalt theory has also the weaknesses that the gestalt theory cannot be applied to certain materials.

Keywords:Learning Theory, Gestalt, Comprehensio

This work is licensed under a Creative Commons Attribution-ShareAlike 4.0 International License. Allows readers to read, download, copy, distribute, print, search, or link to the full texts of its articles and allow readers to use them for any other lawful purpose.

Copyright (c) 2021Sabilla Irwina Safitri, Dwi Saraswati, Esa Nur Wahyuni

Received 04Januari 2021, Accepted 07Februari 2021, Published 11 Mei 2021 


\section{A. Pendahuluan}

Pembelajaran adalah suatu proses mengubah tingkah laku individu yang meliputi pengetahuan, sikap dan keterampilan menjadi lebih baik. Ini bersifat permanen, stabil dan lama dalam perilaku anak yang berasal dari hasil pelatihan atau pengalaman. Proses pembelajaran dapat dipengaruhi oleh individu itu sendiri atau pengaruh eksternal seperti keluarga dan lingkungan sosial (Arifin, 2013).

Belajar merupakan proses interaksi antara individu dengan segala sesuatu yang ada di sekitarnya (Djamarah, 2010). Baik manusia maupun benda dan kondisi sekitarnya. Lingkungan yang nyaman dan aman bagi siswa berpengaruh besar terhadap makna suatu proses pembelajaran.

Pada masa ini, pemaknaan belajar sering kali dilihat sebagai kegiatan mentransfer pengetahuan tanpa memperhatikan pola perilaku dan keterampilan anak. Pandangan ini dikarenakan dalam keluarannya pembelajaran dirasa kurang bermanfaat dan menimbulkan kesan bermakna pada anak. Sehingga banyak anak yang tidak memahami arti sebenarnya dari belajar yang menyebabkan kerusakan moral, hubungan yang salah dan ketidaktahuan.

Pembelajaran dituntut untuk dapat menyelesaikan materi sesuai dengan waktu terlepas dari sejauh mana pemahaman anak terhadap materi yang disajikan. Metode yang membosankan, media pembelajaran yang kurang kreatif atau bahkan hanya satu buku digunakan sebagai sumber belajar. Hubungan emosional antara guru dan siswa yang kurang erat merupakan salah satu faktor kurangnya pemahaman guru terhadap keinginan atau kondisi siswa yang memiliki kelebihan dan kekurangan masing-masing.

Proses tumbuh kembang anak bisa disebabkan oleh faktor genetik atau pengaruh individu dan lingkungan. Berdasarkan teori behaviorisme, anak belajar secara pasif karena anak berpikir secara mandiri. Sedangkan pembelajaran sosial memandang anak sebagai pengolah aktif dengan pengaruh eksternal seperti motivasi, ekspektasi dan figur idola dll di lingkungannya sebagai bahan pembelajaran anak. Namun keduanya saling mempengaruhi pola belajar satu sama lain.

Berbagai teori pembelajaran dalam dunia pendidikan telah diciptakan oleh banyak ahli. Teori belajar pada dasarnya adalah penjelasan tentang bagaimana pembelajaran terjadi atau bagaimana informasi diolah oleh siswa. Teori-teori ini digunakan untuk mendukung pembelajaran anak sesuai dengan tahap perkembangannya. Selain itu juga bertujuan untuk membentuk anak sesuai dengan kebutuhan lingkungan. Teori Gestalt adalah salah satunya. Teori Gestalt menggambarkan proses persepsi dengan mengatur elemen-elemen yang memiliki hubungan, pola, atau kesamaan menjadi satu kesatuan. Teori Gestalt tidak sejalan dengan teori strukturalisme. Teori gestalt cenderung mencoba mereduksi pembagian sensasi menjadi bagian-bagian kecil (Widjajanto, 2018).

Berdasarkan urgensi di atas, pendidik perlu mempelajari berbagai macam teori pembelajaran, salah satunya teori Gestalt, agar dapat menganalisis jenis pembelajaran anak dan menyesuaikan karakter anak sehingga pembelajaran di kelas memberikan kesan dan mudah diterapkan oleh siswa. 


\section{Tokoh Teori Gestalt}

\section{Max Wertheimer}

Max Wertheimer lahir di Praha pada tanggal 15 April 1880 (Pahliwandari, 2016). Pada tahun 1904 Wertheimer lulus dengan gelar Ph.D di bidang psikologi. Perang di Eropa membuatnyapindahke Amerika. Wertheimer menghembuskan nafas terakhir pada 12 Oktober 1943 (Pautina, 2018). Saat Wertheimer dalam perjalanan naik transportasi kereta api, pandangannya tertarik untuk melihat lampu yang berkedip silih berganti pada dalam jarak dan waktu tertentu. Dari peristiwa tersebut, Wertheimer mendapat ide dan hal tersebut menjadi awal penelitian Wertheimer. Berawal dari obyek yang dilihat itu ia tertarik untuk menganalisis dan menemukan jawaban atas pertanyaan-pertanyaan dalam benaknya. Jadi, apabila mata mendapat rangsangan dari suatu obyek maka tercipta sepert ada ilusi gerakan. Peristiwa tersebut dinamakan Phi Phenomenon.

Ketika Wertheimer berusia 30 tahun tepatnya pada tahun 1910, Wertheimer melihat sebuah stroboscope di sebuah toko mainan yang membuatnya tertarik untuk meneliti persepsi. Objek ini membuat Wertheimer tertarik untuk bereksperimen dan mempelajari objek tersebut lebih dalam. Setelah melakukan penelitian dengan stroboscope objek. Wertheimer mencetuskan teori Gestalt yaitu teori persepsi (Pautina, 2018)

2. Wolfgang Kohler

Kohler lahir di Reval Estonia pada tanggal 21 Januari 1887. Ia belajar di Universitas Berlin dan menerima gelar Ph.D. Kohler bertemu Max Wertheimer saat bekerja di Institut Psikologi Frankfurt. Pada tahun 1917, dia menulis bukunya yang paling terkenal, "Mentality of Apes". Pada tahun 1929, dia menulis "Gestalt Psychology". Kohler meninggal pada tanggal 11 Juni 1967 (Indrawati, 2019). Kohler melakukan beberapa penelitian antara lain:

\section{Eksperimen I}

Eksperimen pertama, Kohler melihat sangkar dengan tongkat di atasnya. Kemudian dia memasukkan simpanse ke dalam kandang lalu dia meletakkan pisang di atas kandang tetapi simpanse tidak dapat menjangkau pisang tersebut. Hal ini menarik perhatian simpanse sehingga simpanse berusaha meraih pisang untuk dimakan. Karena merasa kesulitan dan mengalami kegagalan, maka simpanse melihat ada sebatang tongkat di dalam kandang. kemudian simpanse mencoba menggunakan tongkat untuk menggapai pisang diatas kandang, dengan berbagai usaha akhirnya simpanse berhasil meraih pisang yang kemudian dimakannya.

\section{Eksperimen II}

Eksperimen kedua ini masih pada masalah yang sama dengan percobaan pertama. Namun, Kohler memasukkan 2 tongkat ke dalam kandang dan kemudian Kohler mengubah posisi pisangnya lebih tinggi dari sebelumnya. Simpanse mencoba meraih pisang dengan satu batang tetapi simpanse gagal terus menerus kemudian simpanse menemukan pemahaman baru bahwa masih ada satu batang 
lagi, kemudian kedua batang tersebut disambungkan untuk meraih pisang di luar kandang dan akhirnya simpanse berhasil mengambil pisang.

Eksperimen III

Ketiga, dalam percobaan dari Kohler. Dia masih bereksperimen sebagai eksperimen kedua. Namun yang berbeda adalah di sini Kohler mengubah sebatang kayu menjadi sebuah kotak. Awalnya simpanse mencoba mengambil pisang dengan tangan di atas sangkar tetapi simpanse kesulitan meraihnya hingga akhirnya simpanse menemukan pemahaman baru bahwa kotak yang ada di sampingnya diletakkan di bawah pisang kemudian memanjatnya untuk mendapatkan pisang, dan metode ini berhasil.

Eksperimen IV

Dalam percobaan keempat Kohler masih menggunakan simpanse, kandang, pisang dan kotak sebagai penelitiannya, tetapi Kohler menambahkan 2 kotak lagi untuk menambah 3 kotak dan Kohler juga mengangkat pisang. Awalnya simpanse hanya mencoba meraih pisang dengan 1 kotak seperti percobaan ketiga tetapi gagal kemudian simpanse mendapatkan wawasan baru dengan menambahkan kotak kedua namun tetap gagal kemudian simpanse menumpuk 1 kotak lagi hingga kotak menjadi tinggi kemudian simpanse memanjat kotak tersebut. kotak dan bisa mencapai pisang di dalam sangkar.

Dapat disimpulkan dalam percobaan Kohler, bahwa simpanse mampu memecahkan masalah dengan menggunakan pemahaman pengalaman simpanse sebelumnya. 3. Koffka lahir pada 18 Maret 1886. Ia juga lulus di Universitas Berlin dan menerima gelar doktor pada tahun 1908. Kontribusi Koffka untuk psikologi adalah presentasi sistematis dan praktek prinsip-prinsip Gestalt dalam serangkaian gejala psikologis, dari persepsi, belajar, mengingat, hingga belajar psikologi dan psikologi sosial. Teori belajar Koffka didasarkan pada asumsi bahwa pembelajaran dapat dijelaskan dengan prinsip-prinsip psikologi Gestalt. Teori belajar Koffka meliputi: a) Jejak memori, yaitu pengalaman yang membekas di otak. Jejak ingatan ini disusun secara sistematis mengikuti prinsip Gestalt dan akan muncul lagi jika kita mempersiapkan sesuatu yang mirip dengan jejak ingatan sebelumnya, b) Perjalanan waktu mempengaruhi jejak ingatan. Perjalanan waktu tidak bisa melemahkan, melainkan menyebabkan jejak berubah, karena jejak ini cenderung disempurnakan dan disempurnakan untuk mendapatkan Gestalt yang lebih baik dalam ingatan, c) Latihan terus menerus akan memperkuat jejak ingatan (Rohmansyah, 2017).

\section{B. Pembahasan}

\section{Konsep Teori Belajar Gestalt}

Keberadaan teori berawal dari ketidak puasan karakter dengan teori yang telah dikemukakan oleh karakter sebelumnya. Adapun mengenai stimulus dan respon. Menurut gestalt dalam kehidupan, manusia tidak hanya terpaku pada rangsangan dan 
respon tetapi lebih dari itu. Manusia akan mengambil kebijaksanaan dalam segala hal yang mereka alami. Mereka mampu menarik pemahaman tentang berbagai hal dalam pengalaman mereka. Dengan demikian mereka dapat memanfaatkan pemahamannya dengan pemahaman yang saling terkait sesuai dengan peristiwa yang telah di alami.

Teori Gestalt menggunakan konsep-konsep dalam penerapannya. Yang pertama, 'Teori Medan' bahwa tidak ada yang eksis secara terpisah atau terisolasi. Kedua, 'Nature versus Nurture' bahwa otak bukan penerima pasif dan gudang penyimpanan informasi dari lingkungan. Ketiga, 'Hukum Prognanz' bahwa gestaltis sebagai prinsip pedoman mereka dalam meneliti persepsi, belajar, dan memori (Abdullah, 2016).

Teori gestalt memandang belajar sebagai proses pemahaman (insight) yang berbeda dengan teori behaviorisme yang memandang belajar sebagai proses trial and error. Pengertian insight adalah pengamatan dan pemahaman mendadak terhadap hubunganhubungan antar bagian-bagian dalam suatu situasi permasalahan. Seseorang dikatakan berhasil dalam proses belajar jika mendapatkan insight. Dengan adanya insight seseorang akan mengerti permasalahan yang dihadapi dan mampu menyelesaikannya (Wisman, 2020).

Menurut Gestalt, semua Kegiatan pembelajaran menggunakan pemahaman atau pemahaman mendadak pada relasi, mampu memahami makna relasi interrelasi satu sama lain, dapat di fahami juga bahwa di perlukan wawasan untuk mendapatkannya. Masalah konseptual inilah yang terpenting dalam teori Gestalt, bukan mengulang halhal yang harus dipelajari, tetapi memahaminya untuk menambah wawasan (Indrawati, 2019).

Menurut Ernest Hilgard, ciri-ciri belajar pemahaman (insight) yaitu: (1) Keterampilan dasar mempengaruhi pemahaman, (2) Pengalaman sebelumnya dapat mempengaruhi pemahaman, (3) Keadaan dan kondisi juga mempengaruhi pemahaman, (4) Pemahaman dapat dimulai dari percobaan, (5) Proses pembelajaran melalui pemahaman lebih bermakna, (6) Pemahaman dapat diterapkan untuk memahami peristiwa dalam situasi dan kondisi lain (Ariyani, 2020)

Pembelajaran berdasarkan teori Gestalt, merupakan perkembangan kognitif. Seseorang dapat menemukan solusi saat memecahkan masalah. Seseorang pasti memikirkan semua aspek yang diperlukan untuk memecahkan masalah dan menyelaraskan semuanya secara kognitif dengan metode metode lain sampai masalah itu terselesaikan. Setelah menemukan solusi untuk masalah, seseorang dapat menarik pemahaman tentang kejadian tersebut. Karakter Gestalt percaya bahwa solusi dapat ditemukan dan tidak dapat diperoleh.

\section{Hukum dari teori gestalt}

Hukum Pragnanz adalah induk dari tiga sub-hukum dari hukum Gestalt. Hukum tersebut dijabarkan dalam buku karangan Wertheimer berjudul Investigasi Teori Gestalt. sebagai berikut: 1) Hukum Kedekatan, 2) Hukum Penutupan, dan 3) Hukum Kesetaraan (Hidayati, 2011). 


\section{Prinsip-Prinsip Teori Gestalt}

Prinsip-prinsip dalam teori gestalt adalah sebagai berikut: 1) Prinsip pembelajaran berdasarkan teori gestalt meliputi, 2) Belajar secara menyeluruh. Jadi, mengkorelasikan pelajaran antar pelajaran, 3) Pembelajaran merupakan kelanjutan dari materi sebelumnya, 4) Siswa sebagai organisme utuh, 5) Mengalihkan Aktivitas, 6) Belajar merupakan reorganisasi pengalaman, 7) Belajar dengan wawasan, 8) Sukses dalam belajar dipengaruhi oleh kemauan, harapan, dan keinginan seorang anak (Risnawati, 2015).Gestalt juga memiliki prinsip persepsi, yaitu: prinsip kontinuitas dan hubungan figur-ground. (Novalita, 2015).

\section{Kekuatan dan Kelemahan Teori Gestalt}

1. Kekuatan Teori Gestalt: a) Anak mampu menyelesaikan masalah yang ada, b) Belajar lebih bermakna karena siswa menemukan pemahamannya sendiri, dan c) Anak menjadi lebih aktif (Hidayati, 2011).

2. Kelemahan Teori Gestalt Proses pembelajaran suatu pemahaman tidak dapat dijadikan dasar untuk seluruh materi pembelajaran karena ada beberapa fakta atau prinsip. Namun pembelajaran dengan pemahaman sangat penting dalam materi tertentu dan pemahaman dapat kita peroleh jika kita mampu menyelesaikan suatu masalah (Hidayati, 2011).

\section{Penerapan Teori Gestalt dalam Pembelajaran}

Pada kurikulum 2013, pembelajaran diutamakan yang memiliki makna bagi siswa. Maknanya akan membuat ilmu yang diperoleh siswa akan selalu diingat oleh siswa. Salah satu hal yang membuat belajar lebih dekat adalah menemukan sendiri ilmu yang diperoleh.

Pembelajaran berbasis masalah adalah pembelajaran yang diperoleh melalui proses menuju pemahaman penyelesaian suatu masalah (Huda, 2013). Jika termasuk dalam teori Gestalt maka dengan metode problem based learning dapat ditemukan keterkaitan antar keunggulannya. Mereka dapat menyimpulkan suatu ilmu baru setelah mampu memecahkan suatu masalah atau masalah. Siswa yang terlibat dalam menemukan pemahaman untuk dirinya sendiri akan mengingat proses temu kembali. bagaimana dia menemukan, dimana, kapan, dengan siapa, itu akan tetap ada dalam ingatannya bukan sekedar informasi langsung oleh gurunya.

Pembelajaran di sekolah dasar misalnya pada materi sumber energi, siswa akan diberikan arahan untuk mengamankan perambatan panas di udara yang mendidih dengan menggunakan logam seperti sendok saat ibunya memasak, kemudian mereka akan memastikan bahwa materi yang ada di buku tersebut bersama kondisi riil dalam aktivitas mereka sudah benar. Sehingga informasi yang mereka miliki saat membaca buku dengan pengalamannya bersama orang tua akan menjadi pengetahuan dan pengalaman bagi siswa. 


\section{Penelitian Terkait Teori Gestalt}

Beberapa peneliti sudah melakukan riset mengenai penerapan teori Gestalt dalam pembelajaran, diantaranya:

Tabel 1. Hasil penerapan Gestalt dalam meningkatkan kesadaran diri dalam belajar(Oka Mudana, Ketut Dharsana, \& Suranata, n.d.).

\begin{tabular}{cccc}
\hline Peneliti & Siklus I & Siklus II & Keterangan \\
\hline Nyoman Oka & Dari & Dari $81,73 \%$ & Kedua siklus mengalami \\
Mudana, Ketut & $58.93 \%$ & menjadi & peningkatan kesadaran diri \\
Dharsana, dan & menjadi & $88,33 \%$ & dalam belajar setelah \\
Kadek Suranata & $81,73 \%$ & dilakukan treatment \\
\hline
\end{tabular}

Tabel 2. Hasil penerapan Gestalt dalam meningkatkan tanggung jawab siswa(Risma Kusumadewi, Sedanayasa, \& Madri Antari, 2014)

\begin{tabular}{cccc}
\hline Peneliti & Pretest & Posttest & Keterangan \\
\hline $\begin{array}{c}\text { Risma } \\
\text { Kusumadewi }\end{array}$ & $44,6 \%$ & $87,6 \%$ & $\begin{array}{c}\text { Tanggung jawab siswa } \\
\text { meningkat }\end{array}$ \\
\hline
\end{tabular}

Berdasarkan tabel diatas, menunjukkan bahwa Gestalt mampu meningkatkan kesadaran diri siswa dalam belajar, selanjutnya Gestalt juga dapat meningkatkan rasa tanggung jawab siswa sehingga siswa dapat mempertanggung jawabkan hasil belajarnya.

Selain penelitian diatas, beberapa penelitian lain juga menunjukkan adanya dampak positif dalam penerapan teori Gestalt diantaranya, penelitian yang dilakukan oleh Richa Aulya dan Jayanti Putri Purwaningrum tentang penerapan teori Gestalt dalam materi luas dan keliling bangun datar pada SD/MI, dalam penelitian tersebut dijelaskan bahwa bukan hanya hubungan stimulus dan respon saja akan tetapi lebih kepada tujuan yang harus dicapai yakni mendapatkan pemahaman. Siswa akan lebih mudah memahami apabila mereka belajar dengan lingkungan sekitar(Purwaningrum, 2021). Pada pendidikan jasmani, Gestalt mampu mengatasi permasalahan seperti siswa bosan atau kurangnya fasilitas dengan caramengimplikasikan teori belajar Gestalt yang diterapkan sesuai dengan masalah yang dihadapai (Rohmansyah, 2017).

Teori Gestalt juga mampu mengatasi kesulitan belajar pada anak, hal itu dibuktikan oleh penelitian yang dilakukan Amalia rizki pautina, bahwa masalah kesulitan belajar anak bisa diatasi dengan penerapan teori gestalt pada jenjang anak sekolah dasar dengan melalui 6 tahapan, yang pertama adalah identifikasi kasus di mana guru mengelompokkan dan mengumpulkan data anak tersebut, hal ini berguna agar guru mampu memahami anak secara holistik, kedua adalah diagnosis untuk mengidentifikasi masalah anak, ketiga, prognosis yaitu keputusan yang di ambil guru dari data hasil dari diagnosis, selanjutnya keempat, pemberian treatment / perlakuan pada peserta didik sesuai masalah kesulitan yang di hadapi sesuai tahap penyususnan 
prognosis, kelima adalah evaluasi dan yang keenam adalah follow up / tindak lanjut (Pautina, 2018).

Sesuai dengan penjabaran dari berbagai hasil penelitian yang sudah dilakukan mengenai teori Gestalt, dapat diambil titik temu bahwa penerapan teori gestalt dalam pembelajaran mampu memberikan pengaruh positif baik itu meningkatkan hasil belajar maupun mengatasi beberapa permasalahan yang timbul dalam proses pembelajaran. Sehingga, mampu terciptanya pembelajaran yang menyenangkan, bermakna dan selaras dengan pengetahuan yang sudah didapat oleh siswa agar dapat berkelanjutan.

\section{Kesimpulan}

Teori Gestalt memandang bahwa pembelajaran tidak hanya tentang rangsangan dan respon tetapi lebih pada pemahaman tentang masalah yang dihadapi yang mampu menarik kesimpulan baru yang berwawasan. Karakter Gestalt termasuk Max Wetheimer, Wolfgang Kohler dan Kurt Kofka. Dalam teori Gestalt terdapat beberapa hukum yaitu hukum kedekatan, hukum ketertutupan dan hukum persamaan. Diantara prinsip pembelajaran Gestalt adalah pembelajaran melalui wawasan (pemahaman), pembelajaran merupakan reorganisasi dari pengalaman, pembelajaran akan lebih berhasil bila menyangkut minat. Sedangkan prinsip persepsi Gestalt meliputi prinsip kontinuitas dan hubungan figur-ground. Kekuatan teori Gestalt adalah anak mampu merekonstruksi suatu masalah menjadi pengetahuan atau pemahaman baru, namun teori Gestalt ini juga memiliki kelemahan, diantaranya teori Gestalt ini tidak dapat diterapkan pada seluruh materi pembelajaran.

\section{Daftar Rujukan}

Abdullah, A. F. A. (2016). Aplikasi Teori Gestalt dalam Mewujudkan Pembelajaran Bermakna (Meaningfull Learning). Jurnal Edukasi, 2(2), 117-124.

Arifin, Z. (2013). Evaluasi Pembelajaran. Bandung: PT Remaja Rosdakarya.

Ariyani, M. W. dan N. (2020). Teori Belajar dan Implikasinya dalam Pembelajaran. Edu Publisher.

Djamarah, S. B. (2010). Guru dan Anak Didik. Jakarta: Rineka Cipta.

Hidayati, T. N. (2011). Falasifa. Implementasi Teori Belajar Gestalt pada Proses Pembelajaran, 2(1), 12.

Huda, M. (2013). Model-model Pengajaran dan Pembelajaran. Yogyakarta: Pustaka Pelajar.

Indrawati, E. S. (2019). E-Tech. Membangun Karakter Melalui Implementasi Teori Belajar Aliran Psikologi Gestalt Berbasis Kecakapan Abad 21, 7(2), 54.

Novalita, R. (2015). Teori Belajar Menurut Aliran Psikologi Gestalt Serta Implikaisnya Dalam Proses Pembelajaran. Lentera, 15(15), 34. 
Oka Mudana, N., Ketut Dharsana, I., \& Suranata, K. (n.d.). Penerapan Konseling Gestalt Dengan Teknik Reframing Untuk Meningkatkan Kesadaran Diri Dalam Belajar Siswa Kelas Viii A1 Smp Negeri 4 Singaraja Tahun Ajaran 2013/2014. ejournal Undiksa Jurusan Bimbingan Konseling, 2(1).

Pahliwandari, R. (2016). Penerapan Teori Pembelajaran Kognitif dalam Pembelajaran Pendidikan Jasmani dan Kesehatan. Jurnal Pendidikan Olahraga, 5(2), 154-164.

Pautina, A. R. (2018). Tadbir. Aplikasi Teori Gestalt dalam Mengatasi Kesulitan Belajar Anak, 6(1), 15-16.

Purwaningrum, R. A. dan J. P. (2021). Penerapan Teori Gestalt dalam Materi Luas dan Keliling Bangun Datar Untuk SD/MI. Jurnal MathEdu, 4(1), 1-9.

Risma Kusumadewi, K., Sedanayasa, G., \& Madri Antari, N. N. (2014). Penerapan Efektivitas Konseling Gestalt Dengan Teknik "Saya Bertanggung Jawab Atas...." Untuk Meningkatkan Tanggung Jawab Akademik Siswa. Jurnal Online Jurusan Bimbingan Konseling, 2(1).

Risnawati, Z. A. dan. (2015). Psikologi Pembelajaran Matematika. Yogyakarta: Aswaja Presindo.

Rohmansyah, N. A. (2017). Implikasi Teori Gestalt dalam Pendidikan Jasmani Sekolah Dasar. Malih Peddas, 7(2), 197.

Widjajanto, D. (2018). Teori Gestalt.

Wisman, Y. (2020). Teori Belajar Kognitif dan Implementasi dalam Proses Pembelajaran. Jurnal Ilmiah Kanderang Tingang, 11(1), 209-215. 